\title{
Análise da produção e comercialização de óleo vegetal no Brasil: o estudo de caso da empresa Cargill
}

Analysis of the production and sale of vegetable oill: the case study of the Cargill Company

\section{Resumo}

Desde a década de 70, a produção de óleos vegetais vem tomando proporções consideráveis. O óleo de cozinha em substituição aos tradicionais métodos de fritura e culinária em geral, tem se destacado considerando várias oleaginosas como: soja, milho, canola, algodão, amêndoa e etc. De acordo com o Food and Drug Administration - FDA e a Associação Americana de Doenças do Coração - AHA, o consumo de óleos vegetais é benéfico para todos e isso inclui o consumo de óleo em si. Presente em quase todos os lares brasileiros, os óleos vegetais têm trazido inovações consideráveis desde a sua pressurização até as inovações de logística e transporte. Percorrendo o caminho da empresa Cargill, encontra-se o seu carro chefe: o óleo da linha Liza. Desta feita, observou-se os aspectos específicos envolvidos no market-share e nas inovações de processo do mesmo. O objetivo do presente trabalho é apresentar o desenvolvimento do modelo de negócio da empresa Cargill como casamento exitoso entre mercado e meio ambiente.

Palavras-chave: Óleos vegetais; Meio ambiente; Economia.

\begin{abstract}
Since the 70s, the production of vegetable oils has taken considerable proportions. The cooking oil, replacing traditional frying methods and cooking in general, has been highlighted considering several oilseeds such as: soybeans, corn, canola, cotton, almonds, etc. According to the Food and Drug Administration - FDA and American Heart Disease Association - AHA, the consumption of vegetable oils is beneficial for everyone and that includes the consumption of oil itself. Present in almost every Brazilian household, vegetable oils have brought considerable innovations from their pressurization to logistics and transport innovations. Traveling along the path of the Cargill company, you will find the flagship that is the Liza line oil. This time, the specific aspects involved in market-share and its process innovations were observed. The objective of this work is to present the development of the business model of the Cargill company as a successful marriage between the market and the environment.
\end{abstract}

Keywords: Vegetable oils; Environment; Economy.

\section{Introdução}

Até os anos 60, a produção e comercialização do óleo de cozinha eram feitas por companhias distintas, fatores estes que causaram custos de oportunidade no que tange à abrangência do mercado e o aparecimento de externalidades. A empresa Cargill conseguiu unir essas duas pontas de sua produção de óleos vegetais finalizando-as com as melhores condições de funcionamento e economias de escala.

A importância do market-share expandido, oportunizou uma expansão na linha de óleo de cozinha, além de viabilizar a entrada de outras oleaginosas que proporcionaram ganhos de mercados de vizinhos concorrentes a baixo custo. As expectativas de mercados mais atraentes foram proporcionadas pela conquista do mercado local e pela dominação de fornecedores que trabalharam de maneira consorciada. Desta forma, eliminando externalidades e apontando trajetórias de inovação de processo, dominou-se grande parte do mercado de óleos vegetais pressurizados. 


\section{Metodologia}

Segundo Lakatos \& Marconi (2007) toda pesquisa requer uma metodologia formal que solicita um tratamento científico e se estabelece a passagem para se reconhecer a realidade ou para encontrar verdades parciais. Dessa forma contamos com três etapas do tipo foco causal (causes of effects): 1- pesquisa exploratória pois o estudo de caso em tela reforça fundamentar a teoria da inovação de processo e produto com a prática da empresa Cargill; 2- Comparação e exaustão - destaca-se o itinerário de eficiência da empresa e seus resultados auferidos e 3- As possíveis inferências causais do tipo efeito da propaganda no aumento do mix de produto. Esta pesquisa tem por base a metodologia de estudo de caso, onde se utilizou o estudo do beneficiamento e a produção de óleo vegetal de soja Liza aliados às inovações de processo.

\section{Resultado e Discussão}

Fundada em 1865, nos EUA, por William Wallace Cargill, levando seu sobrenome como logomarca, a Cargill tornouse uma das maiores promotoras de beneficiamento de óleo de cozinha do mundo utilizando praticamente a soja como carro chefe. Além disso, a empresa é referência mundial na oferta de serviços e produtos alimentícios, agrícolas, pastagens e máquinas industriais para pressurização de oleaginosas. Atuando há mais de 155 anos, essa empresa vem transformando e ampliando qualidade no setor que abrange, juntamente com produtores rurais, governo e comunidades, atuando em cerca de 70 países, juntamente com 155.000 funcionários.

Figura 1 - Logomarca da Cargill.

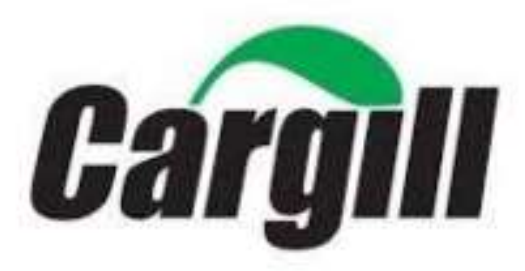

Fonte: arquivos Cargill (2019).

Tendo como um dos focos, promover a alimentação saudável, segura, sustentável e acessível do campo ao consumidor, a Cargill está no Brasil desde 1965, atualmente ela opera em 17 estados brasileiros e no Distrito Federal, por meio de unidades industriais, além de contar com cerca de 147 escritórios nos municípios. 
Figura 2 - Empresa Cargill do Brasil.

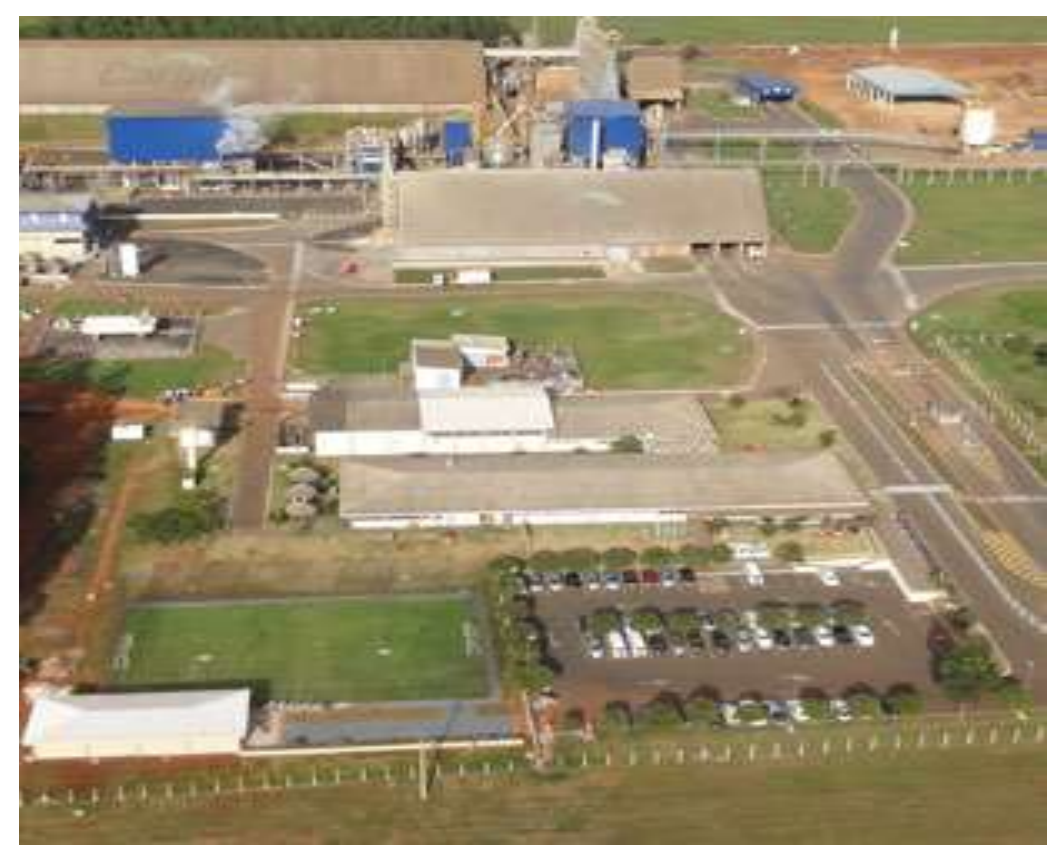

Fonte: Cargill do Brasil - Uberlândia - MG (2019).

\subsection{Produção de Óleo}

Do lema "Liza na panela, no prato,no lanche, na salada...na cozinha” nasce uma paixão nacional. Os óleos vegetais da Cargill entram com um selo de qualidade $3 \mathrm{~S}$ - que quer dizer soluções para suprimentos sustentáveis - respeitando ao The nature conservancy e ao código florestal brasileiro (CAR) que adotam práticas sustentáveis e contam com $96 \%$ de pequenos agricultores familiares aliados.

Existe diversos produtos atrelados ao mix produzidos pela Cargill que vão além dos óleos de cozinha e ampliaram no último decênio mais 400 milhões de reais em investimentos nas 17 unidades do território brasileiro.

Figura 3 - Mix de produdos.

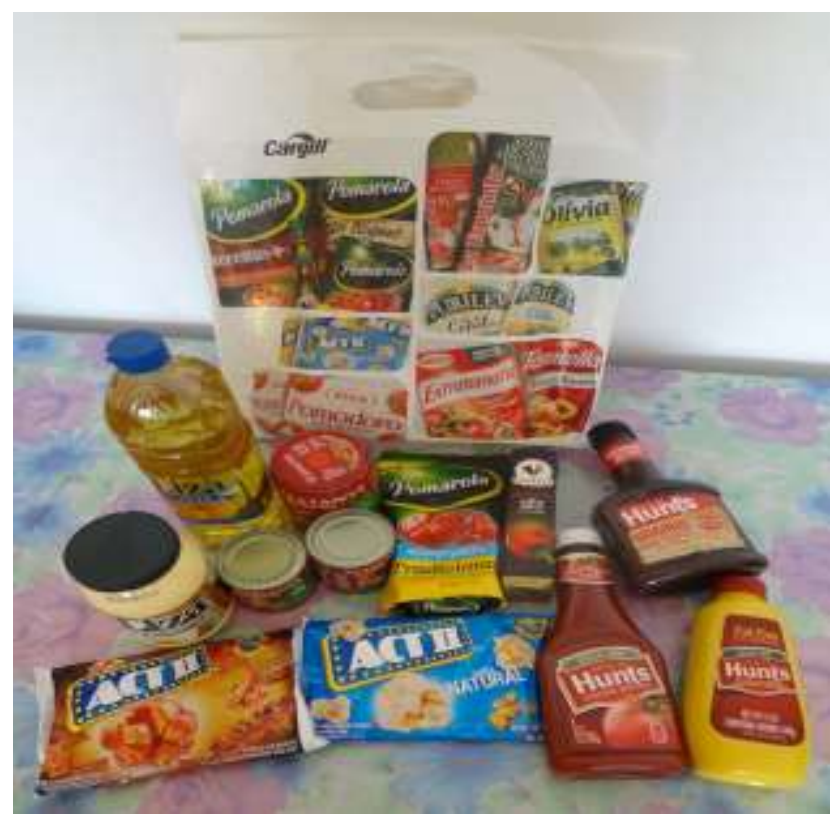

Fonte: Mix de produtos - Relatório Cargill (2019) 
Dentro da produção, a variedade do mix de produtos é um dos fatores mais importantes na companhia. Com uma grande diversificação e com a adesão de novas técnicas de logística, o mix de produtos comercializados cresceu sendo a seleção de gramatura, acondicionamento e seleção de linha, as principais metas. Isso, criou através dos tempos, uma barreira natural à entrada de novos concorrentes

Kupfer e Hasenclever (2013) destacam que as economias de escopo podem ser benéficas já que ao produzir dois bens diferentes, seus custos de produção quando estão atrelados, geralmente são menores do que quando são produzidas separadamente (algumas empresas conseguem reduzir seus custos médios com a diversificação de produtos). Então a Cargill se desempenha formando vários produtos da linha Liza, que além de ser a mais popular, casa-se com a política de incentivos fiscais do uso de várias oleaginosas locais.

A Cargill apresenta a linha de produtos LIZA, onde se tem o óleo produzido e comercializado no Brasil há mais de 45 anos. A magnitude da produção envolve diversos tipos de óleo de cozinha da linha Liza. Essa diversificação envolve óleos produzidos usando a técnica de beneficiamento uninuclear, ou seja, só de milho, ou só de soja, ou só canola.

Geralmente a especialização em tal produto, corresponde em termos de grandes lotes a busca pela redução de custos; Mas a forma de produzir bens agregado que tem relação com insumos ou mercados, acaba acarretando melhores custos além de não precisar aumentar sua produção. Portanto a Cargill ampliou seus produtos próximos para elaborar um mix capaz de assegurar seus custos e elevar sua produção sem piorar os custos.

\subsection{Decisões Importantes}

Durante sua trajetória, a Cargill se deparou com estratégias de concorrência através de imposição de marcas acerca dos produtos novos. Dessa forma, a administração começou a perceber que os consórcios com novas concorrentes poderia ser uma vantagem cooperativa que facilitaria uma ação de ganho de território. A Cargill começou a adquirir novos mixes e novos integrantes, além de ampliar a qualidades de suas compra, mas divulgando marcas associadas como parte de seu grupo.

A Empresa inovou em termos de Estrutura-Conduta-Desempenho (ECD), pois passou a ver novas forma de se ampliar no mercado, não só "criando o produto em si"; mas comprando e aprimorando as ideias já existente no mercado, causando assim o comercial de sua marca; lembramos que os principais elementos-chave do ambiente interno que causam a estrutura do mercado; são os procedimentos de estratégias competitivas e o desempenho dos resultados em termos de lucratividade e faturamento.

Os novos produtos apresentam também vantagens competitivas em termos de propaganda, uma vez que existem formas mais agressivas para estabelecer sua imagem diante de outras marcas. Sendo assim, configura-se uma barreira praticamente nova à concorrência. Geralmente, isso ocorre em mercados de produtos relativamente homogêneos voltados para o grande público.

Um outro ponto, é o investimento decisivo que é a relação direta com o produtor, esta união com o próprio produtor de soja e outras matérias primas, ajuda na parte de qualidade dos produtos que os produtores oferecem para a Cargill. Esse apoio que a Cargill oferece aos produtores, acarretou um melhor produto final, ocasionando a formação de consórcio produtor familiar - empresa cujos critérios são preço e qualidade dos insumos.

\section{3 Óleo de Soja}

A soja é o carro-chefe no tocante a seleção de insumos. Um critério adotado pela empresa e muitas outras, além de instituição, desde 2006, foi a Moratória da Soja, que é um acordo setorial em que as empresas se empenham a não comercializar nem financiar soja cultivadas em áreas que foram desmatadas no bioma Amazônia após 2008. Com o aparecimento do MATOBIPA, essas técnicas e outras medidas, trazem para a população um aspecto sustentável ao qual demostra que a Cargill tem uma meta conservacionista, não obstante não fragilizando o seu mix de produtos. 
De acordo com Kupfer e Hasenclever (2013), essa união desenvolveu um tipo de APL centrado em uma mesmo região, além de paralelo ao programa oficial de São Paulo, empresas do setor têm seus projetos relacionados à questão. É a especialização produtiva e alguma forma do tipo de progredir com a articulação, interação, cooperação e aprendizagem entre eles ou até mesmo com da mesma região a exemplo as instituições de crédito ensino, pesquisa, além do governo, e associações empresariais, assim como outros com formalidade próxima. Essas técnicas melhoram a qualidade do meio ambiente e é uma inovação de marketing, ou seja, é uma das formas de inovar, e que pode ser definida como a utilização de métodos/ferramentas/técnicas novas para comercializar os produtos e serviços da empresa, contendo desde uma mudança significativa na embalagem até um completo reposicionamento de marca.

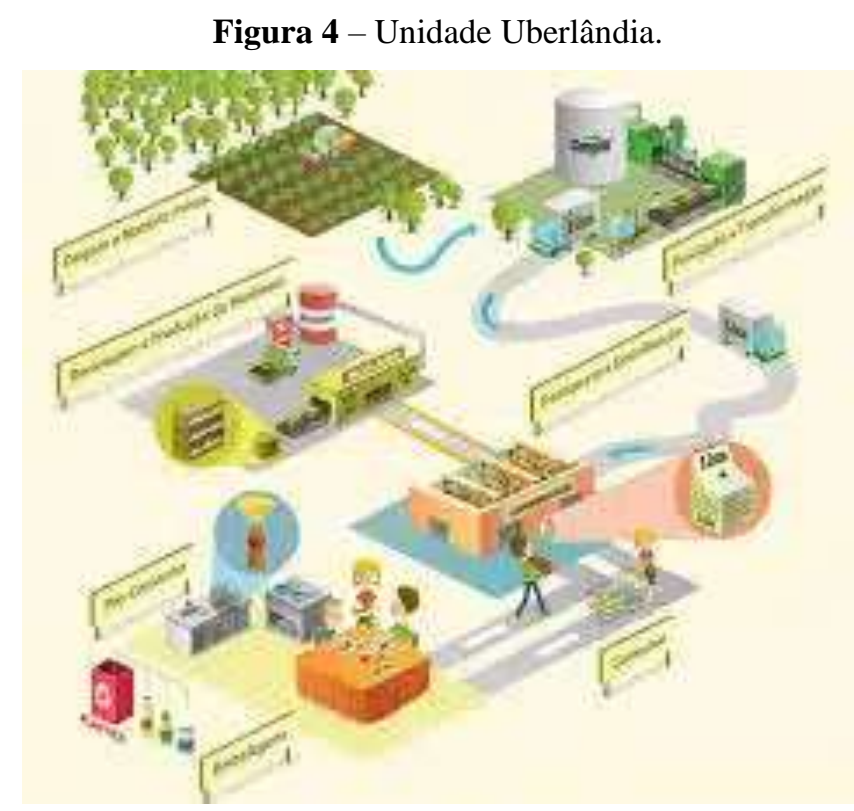

Fonte: Oliveira \& Ruiz - Semead (2014) apud Relatório Cargill 2013 - unidade Urberlândia.

Quando se trata da produção de óleo vegetal, deve-se atrelar precisamente à produção de biodiesel, onde se encontra grande parte da destinação dos mesmos produtos que também são insumos da produção de óleo de cozinha. A partir disso, temse a precisão em relatar que as previsões em inovação para o setor é que até 2028 diversificar ainda mais os produtos centrais conhecidos como produtos metas - para obtenção de óleo. Outrossim até 2035, a Cargill pretende aumentar o setor de esmagamento de oleaginosa, contribuindo para o replantio de áreas consideradas de terra morta, passando dos atuais $40 \%$ para $65 \%$ dos insumos..

\subsection{Análise de Dados}

Segundo dados extraídos da ABIOVE (Associação Brasileira das Indústrias de Óleos Vegetais), vê-se a produção por estado brasileiro e sua respectiva participação no processamento, refino e envasamento do óleo de cozinha. A liderança é o do estado do Matogrosso tradicionalmente produtor de soja, seguidos do Sudeste, com o Paraná e o Rio Grande do Sul, e no Nordeste aparecem o Piauí, Maranhão, e o Ceará que são os destaques mas estes dividem este cenário com consórcios peculiares das cultivares arroz, milho e canola. Essa análise demonstra que a soja ainda é o carro chefe na definição do refino do óleo vegetal de cozinha no Brasil mas devido a política ambiental do selo 3S a qual a Cargill leva a cabo, os demais estados brasileiros fora do cinturão tradicional de produção também estão se destacando através da produção de outras oleaginosas. 
Quadro 1 - Capacidade instalada da indústria brasileira de óleos vegetais (ton/dia).

\begin{tabular}{|c|c|c|c|}
\hline Estado & $\begin{array}{l}\text { Processamento } \\
\text { Ton/dia }\end{array}$ & $\begin{array}{l}\text { Refino } \\
\text { Ton/dia }\end{array}$ & $\begin{array}{l}\text { Envasamento } \\
\text { Ton/dia }\end{array}$ \\
\hline Mato Grosso & 42501 & 3489 & 3108 \\
\hline Paraná & 35940 & 3280 & 2119 \\
\hline Rio Grande do Sul & 30489 & 1020 & 930 \\
\hline Goiás & 26968 & 3093 & 2562 \\
\hline São Paulo & 14031 & 5060 & 2130 \\
\hline Mato Grosso do Sul & 12250 & 408 & 365 \\
\hline Minas Gerais & 9328 & 2206 & 1023 \\
\hline Bahia & 7323 & 1096 & 1018 \\
\hline Piauí & 3050 & 120 & 180 \\
\hline Tocantins & 2900 & - & - \\
\hline Santa Catarina & 2200 & 600 & 199 \\
\hline Amazonas & 2000 & - & - \\
\hline Maranhão & 1500 & 300 & 340 \\
\hline Ceará & 1000 & 200 & - \\
\hline Rondônia & 350 & - & - \\
\hline Pernambuco & - & 763 & 132 \\
\hline Total & 191830 & 21634 & 14106 \\
\hline
\end{tabular}

Fonte: ABIOVE - Gerência de economia e estatística - Ano ref. 2019-dados relatório -2020.

Após uma adaptação dos dados, chegou-se ao Gráfico 1 abaixo:

Gráfico 1 - Gráfico de capacidade instalada da indústria brasileira de óleos vegetais (ton/dia) porcentual.

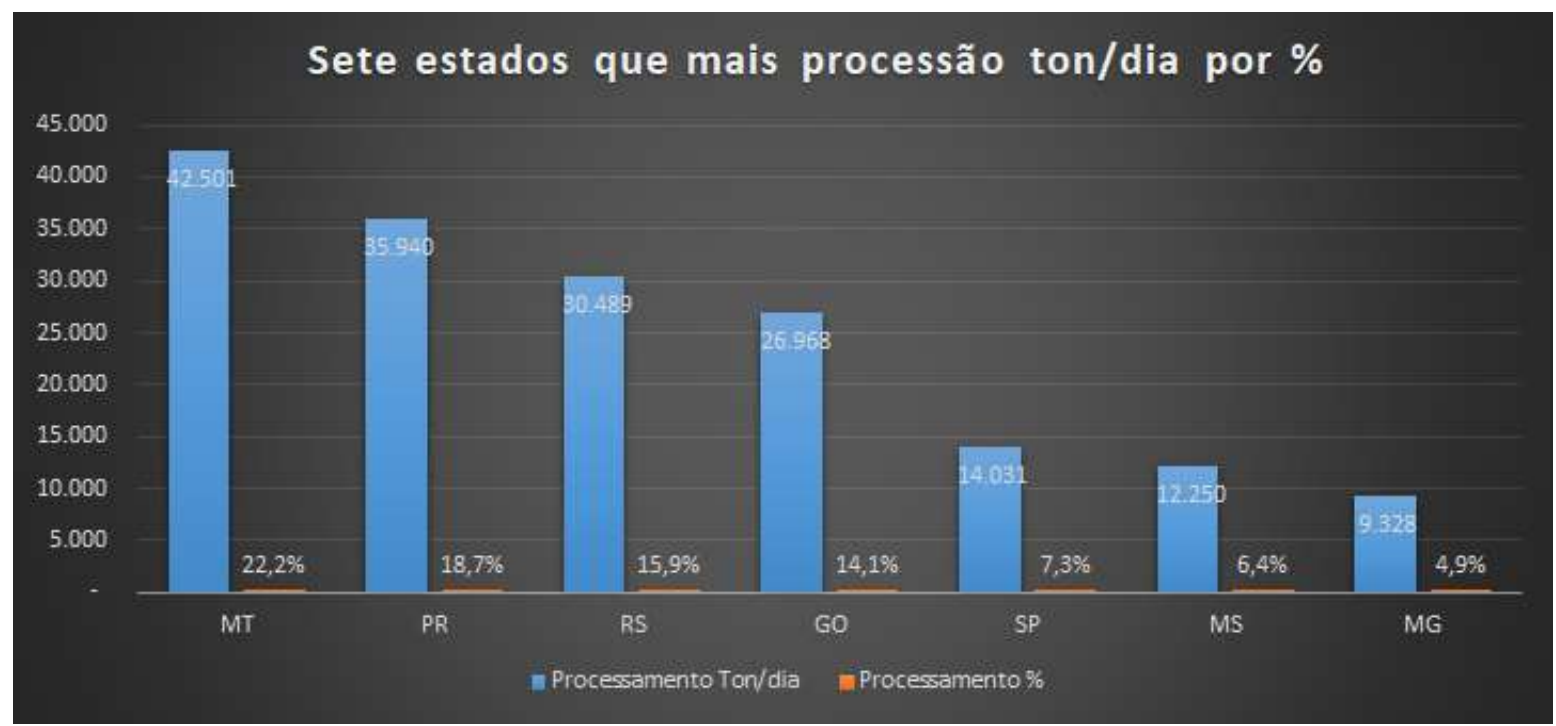

Fonte: elaboração própria a partir dos dados da Cargill 2021. 


\section{Conclusão}

Chegou-se a entendimentos finais que a Cargill tem um vasto histórico de investimentos sempre tentando inovar olhando com muito cuidado sua proximidade do produtor familiar, oferecendo assim um produto de preço accessível ao consumidor final. Além de investimentos na parte de maquinário e tecnologias de automação, a Cargill implementou na última década uma linha com vasto mix de produtos do tipo substituto perfeito que fez com que a Cargill se tornasse uma das principais promotoras de eficiência com selo de qualidade 3S. Assim, qualquer empresa que for entrar no mercado, se depara com uma barreira do tipo natural.

\section{Referências}

Branski, R. M et al. (2006) Metodologia de estudo de caso aplicada à logistica.

Cargill (2021 Óleos de Cozinha. https://www.cargill.com.br/pt_BR/\%C3\%B3leos-de-cozinha

Cargill (2021.) Nossa História. https://www.cargill.com.br/pt_BR/nossa-hist\%C3\%B3ria

Cargill (2021) Inicio. https://www.cargill.com.br/pt_BR/in\%C3\%ADcio

Cargill (2021)Relatórios Anteriores. https://www.cargill.com.br/pt_BR/relat\%C3\%B3rios-anteriores

(Cenarioagro,(202http://www.cenarioagro.com.br/logistica-reversa-do-oleo-decozinhaProteger o planeta

https://www.cargill.com.br/pt_BR/prote\%C3\% A7\%C3\%A3o-do-planeta Elsevier, ISBN 978-85-352-6368-8 1. Organização industrial (Teoria econômica). 2. Política industrial - Brasil

Empresa Brasileira de Pesquisa Agropecuária (Embrapa). (2006)

Empresa Brasileira de Pesquisa Agropecuária (Embrapa). Brasil (2008)

Empresa Brasileira de Pesquisa Agropecuária (Embrapa). Brasil (2009)

Hasenclever, L. \& D. Kupfer (2013) Economia industrial: fundamentos teóricos e práticas no Brasil / organizadores, (2.ed.) Rio de Janeiro:

Lakatos, E. M; \& Marconi, M. A. (2003) Fundamentos de metodologia científica. (5 .ed.). Atlas 312p. ISBN 85-224- 3397-6

Liza.com.br

Murphy, A. (2020). As 25 maiores empresas privadas dos Estados Unidos em 2020 Forbes.

Sibalde, S. (2021) Logística reversa do óleo de cozinha.

Oliveira, R. \& Ruiz (2014) Cadeia produtiva de óleo de cozinha usado: caracterização dos principais atores do arranjo produtivo existente na Região Metropolitana de São Paulo. 